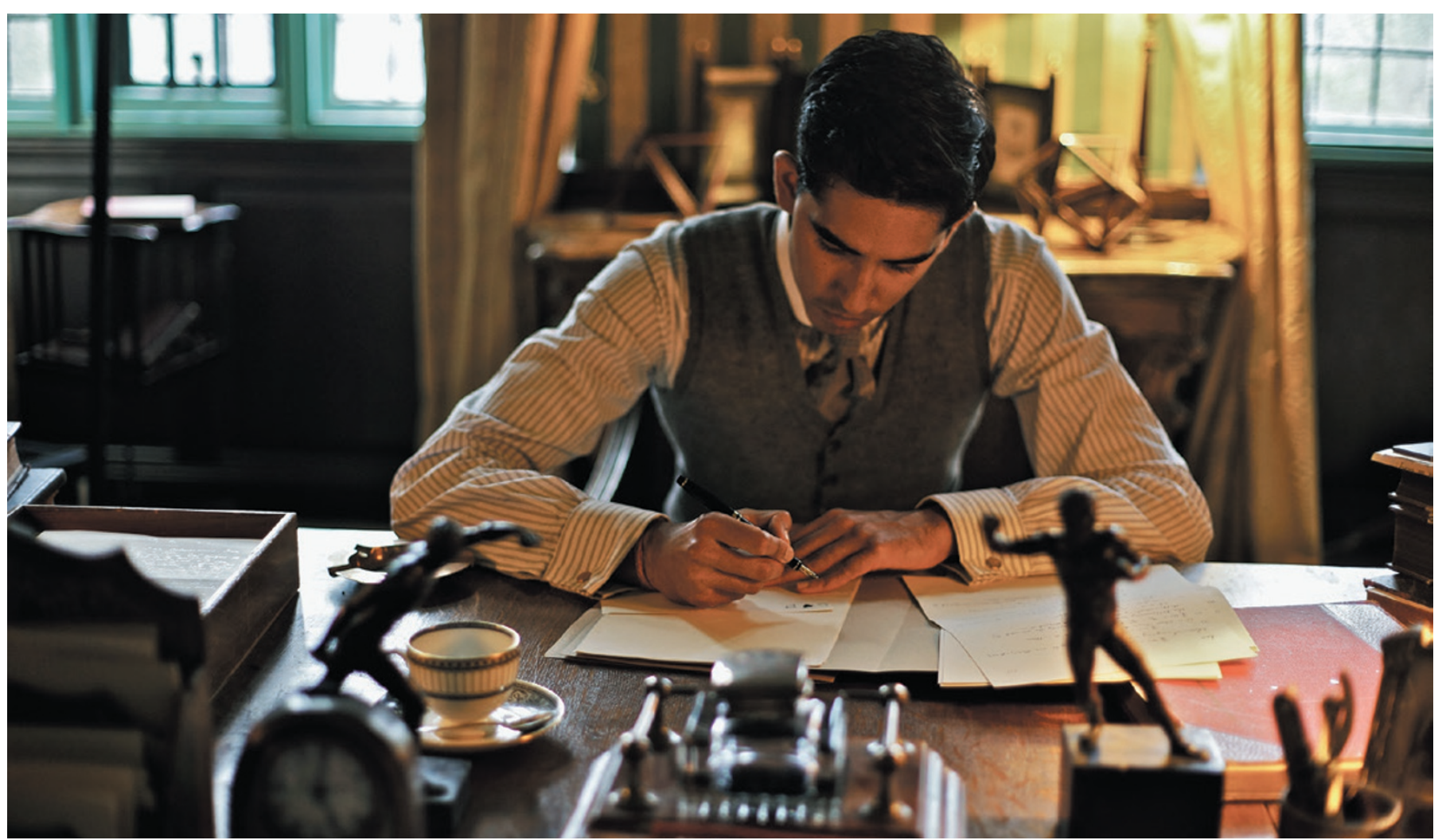

Dev Patel stars as Srinivasa Ramanujan in The Man Who Knew Infinity.

\title{
In search of Ramanujan
}

Andrew Robinson marvels afresh at the self-taught mathematical genius in a new biopic.

$\mathrm{T}$ he story of the Indian mathematician Srinivasa Ramanujan (1887-1920) is improbable. Self-taught, he made many seminal discoveries in number theory and power series - most famously concerning the partition of numbers into a sum of smaller integers - that continue to fascinate mathematicians and intrigue physicists studying black holes and quantum gravity. In The Man Who Knew Infinity, director Matthew Brown dramatizes the purest of mathematics for a general audience, and explores the strange personal life of Ramanujan, who died at 32, at the height of his powers, probably from tuberculosis. Based on the compelling biography of the same name by Robert Kanigel (Scribner, 1991), the film took more than ten years to create. It is worth the wait.

Ramanujan's career was 'made' by British mathematician G. H. Hardy, a fellow of Trinity College, Cambridge. In 1913, while working as an accounts clerk in what is now Chennai, Ramanujan sent Hardy startling, entirely unproven, theorems out of the blue. "They must be true," wrote Hardy, "because, if they were not true, no one would have the imagination to invent The Man Who them." Hardy lured Knew Infinity Ramanujan to Cam- WRITTEN AND bridge, even though DIRECTED BY foreign travel was MATTHEW BROWN considered an offence Films/Animus Films: against Hindu caste 2016. purity. They collaborated intensively throughout the First World War. Ramanujan had no university degree, but in 1918, Hardy ensured that he was elected a fellow of the Royal Society - the first Indian to receive the honour after it was restricted to scientists - and of Trinity College. They encountered considerable opposition, some of it racially motivated.

Hardy's relationship with Ramanujan holds the film together. Convincing performances by Jeremy Irons as Hardy and Dev Patel as Ramanujan were carefully refined by the film's Japanese-American mathematics adviser, Ken Ono, whose academic career has been dedicated to exploring Ramanujan's theorems. Irons and Patel animate both the consuming passion for mathematics shared by the two, and their astonishing lack of personal intimacy; Hardy, for instance, had only a faint idea of Ramanujan's growing depression, which led to a suicide attempt on the London Underground. Irons, however brilliant, is a generation older than Hardy was in 1914, and Patel is taller and nattier than the more corpulent Ramanujan, who was ill at ease in Western dress.

Much of the action - and mathematics - takes place in the handsome precincts of Trinity College, which opened its doors to a feature film for the first time. In Hardy's room and the quadrangles, Ramanujan persistently resists Hardy's demands for proofs of his tantalizing theorems. An excited Ramanujan infuriates a lecturer by failing to take notes and then quickly chalking a correct formula: a very special integral due to Carl Friedrich Gauss, which Ramanujan knew through a method of his own devising. And in an evocative scene in Trinity's Wren Library, the famously atheistic Hardy tells his Indian protégé that the greatest honour "is to have a

\section{$\rightarrow$ NATURE.COM} For more on science in culture see: nature.com/ booksandarts 
legacy at Wren once we are gone. In this very library are the Epistles of St Paul, the poems of Milton, Morgan's Bible and, in my estimation as a man of numbers, the pièce de résistance, Newton's Principia Mathematica." Ramanujan's 'lost notebook' - which contains important mathematical discoveries made in India in 1919-20 and was neglected until 1976 - is, fittingly, in the Wren Library.

Scenes in India are no less ravishing. We see Ramanujan in flowing Indian clothes with Brahminical caste marks, chalking endless equations on the floors of a highly decorated Hindu temple. His dominating mother Komalatammal and wife Janaki provide a glimpse of domestic life. Indian and British colonial figures come and go (with a cameo by Ramanujan admirer Stephen Fry). But the film struggles to shed light on the origins of Ramanujan's prodigious gift. Biographers have had the same problem with Gauss and many other mathematicians. As India's great film director Satyajit Ray put it: "This whole business of creation, of the ideas that come in a flash, cannot be explained by science."

Hardy, too, was dazzled and puzzled. On a 0-100 scale of natural mathematical ability, he gave himself a score of 25 and Trinity colleague John Littlewood (a fellow supporter of Ramanujan) 30, compared with 80 for influential mathematician David Hilbert and 100 for Ramanujan. "The limitations of his knowledge were as startling as its profundity," Hardy wrote after Ramanujan's death. "All his results, new or old, right or wrong, had been arrived at by a process of mingled argument, intuition and induction, of which he was entirely unable to give any coherent account."

Ramanujan has inspired many. Christopher Sykes's pioneering UK television documentary, Letters from an Indian Clerk, was screened in 1987. The play A Disappearing Number, devised by Théâtre de Complicité, was produced in Britain in 2007 (see Nature 449, 25-26; 2007). A biographical novel by David Leavitt, The Indian Clerk (Bloomsbury), was published in 2007.

Now, the film has spawned an intriguing, moving autobiography by Ono, My Search for Ramanujan (Springer, 2016), written with science writer Amir Aczel, who died before publication. Ono interweaves Ramanujan's life and work with his own fight to become a mathematician - including a suicide attempt — in the shadow of his distinguished mathematician father, Takashi Ono. After years of estrangement, the Onos realized that they were united by admiration and affection for the university drop-out Ramanujan. Here is yet another example of how this enigmatic Indian's unique achievements continue to reverberate nearly a century after his death.

Andrew Robinson is the author of Genius and Satyajit Ray: The Inner Eye. e-mail:andrew@andrew-robinson.org

\section{PSYCHOLOGY}

Time piece

\section{Hedderik van Rijn weighs up an erudite but idiosyncratic survey of how we perceive life passing.}

$\mathrm{T}$ The sense of time passing plays a pivotal part in decision-making from choosing chicken or pasta on a long-haul flight to deciding whether to propose marriage to a long-term partner. Although the temporal resolution in these scenarios differs by orders of magnitude, Felt Time by psychologist Marc Wittmann (first published in German as Gefühlte Zeit; C. H. Beck, 2014) argues that the experiences are closely related.

Wittmann marshals a wealth of behavioural and neuroscience results, as well as references to the arts, literature and philosophy, to argue that how we subjectively experience time determines whether we are able to seize the day and live happy and fulfilled lives, or struggle to finish our daily chores. He urges us to strive to slow down subjective time and to live in the here and now. Inspired by the Roman Stoic philosopher Seneca, his suggestion for cultivating presence is to abstain from busywork - to get rid of the "unconditional work ethic" that drives us back to our desks on sunny Sunday afternoons to finish yet another grant proposal instead of relaxing. Another, more pragmatic, proposal for slowing down subjective time is 'mindfulness. By using meditation

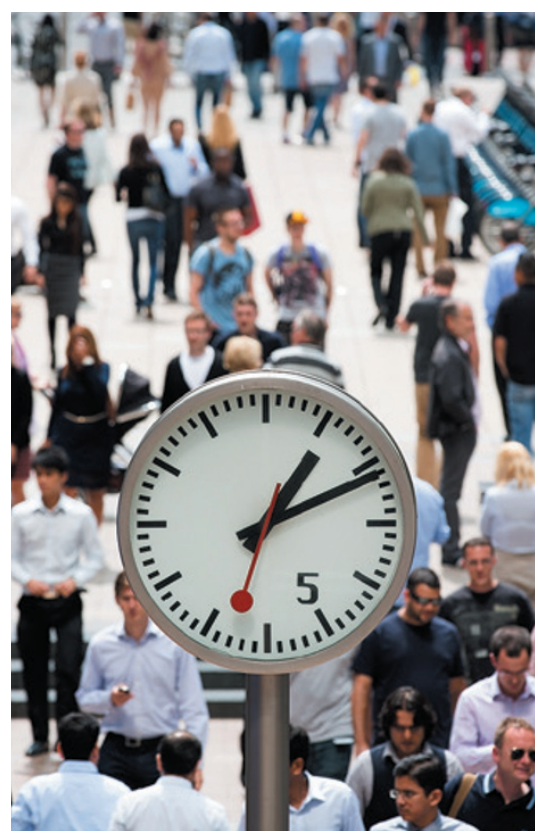

Perceived and measured time may not always match.

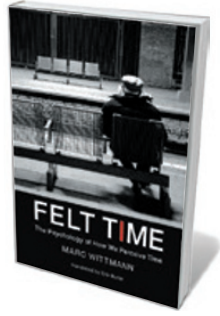

Felt Time: The Psychology of How We Perceive Time MARC WITTMANN (TRANSLATED BY ERIK BUTLER)

MIT Press: 2016.

$$
\text { MIT Press. } 2016 .
$$

techniques such as a focus on breathing, Wittmann argues, we become more aware of our inner body states, more "mentally present"; this slows down our subjective time, resulting in more fulfilling in - the-moment experiences.

I am not convinced that mindfulness can help in all contexts discussed in Felt Time, because Wittmann defines time very loosely. He links the perception of seconds with perception over months or years. He elides the effects of circadian rhythm and chronotype (whether someone is a 'morning' or 'evening' person), youthful impatience, the observation that years seem to pass faster as we age, and the prospect of dying - the ultimate time limit. Although all of these are associated with our perception of life passing, each has a distinct aetiology: circadian rhythms are driven by wellknown biological circuits, for example. But the change in subjective time with age is attributed to experiencing fewer unfamiliar (and therefore memorable) events, something that could be more easily influenced than circadian rhythms.

I do, however, strongly agree with Wittmann's implicit arguments for a more inclusive study of time. Beyond simple laboratory studies of temporal cognition tasks, Wittmann makes the case that science should explore how perceived time affects everyday activities, as well as how everyday activities influence our perception of time. But rather than conducting lab work in which participants must estimate the duration of intervals marked with clear start and end points, we should consider timing as a continuative process: every task we do is timed, irrespective of whether we know at the start that time might become important.

Felt Time is divided into two parts. In the first, Wittmann introduces the important role of time in many aspects of everyday 